\title{
Exequias celebradas en el reino de Chile por Carlos III
}

\author{
Jorge Chauca García \\ Universidad de Málaga
}

\begin{abstract}
RESUMEN ABSTRACT
Las exequias y actos por la muerte de Carlos III vieron cómo la periferia indiana se esforzaba en sumarse al conjunto de celebraciones que por todos los territorios de la monarquia fortalecian los lazos de la Corona con sus súbditos. El reino chileno, a pesar de su situación geográfica marginal respecto al centro, organizó todo el ceremonial acostumbrado para ratificar una vez más la continuidad monárquica por encima del cambio de rey. La naturaleza de sociedad de frontera y su dinámica interna hacian más que necesario la revalidación del pacto atlántico, visualizado en las honras por el monarca difunto y su programa iconológico de exaltación real e identidad hispana.

The funeral rites and ceremonies because of Carlos III death's showed how the Spanish American were making efforts to add up to the set of celebrations taking place all over the territories of the monarchy that strengthen the tie of the Crown towards its subjects. The Chilean kingdom, despite its outcast geographical position with respect to the centre, organized all the ceremonial as usual to ratify once more the monarchy continuity over the king succession. The nature of frontier society and its internal dynamics, made the ratification of the Atlantic pact more than necessary, visualized on the rites for the deceased king and on its royal glorification and Hispanic identity iconological program.
\end{abstract}

Las fiestas extraordinarias o repentinas cuya causa estaba relacionada con algún acontecimiento que afectara a la familia real alteraban la vida cotidiana indiana despertando tristeza o regocijo. Las exequias fúnebres transmitían lutos y honras por el distante monarca fallecido y se prolongaban de modo natural con las grandes alegrías subsiguientes a la proclamación del nuevo rey, en una fiesta cuyo medio y fin último era el triunfo de la lealtad. Estos ceremoniales de contenido político-cívico y religioso constituian el eje de una estrategia encaminada a legitimar el orden colonial mediante la exaltación de la monarquía en sus momentos de re- 
ajuste, cuando las autoridades desplegaban todos los símbolos ideológicos de reafirmación y fidelidad colectiva. Las ciudades americanas contemplaron, con gran solemnidad y entusiasmo, una pléyade de fiestas reales cuyos escenarios principales lo constituían la Plaza mayor o de Armas y la Catedral, espacios de liturgia del poder regio sacralizado idóneos para manifestar la adhesión integral de la sociedad indiana a la Corona, especialmente con ocasión de óbitos y juras. Aparte de las peculiaridades regionales ${ }^{1}$, los actos oficiales celebrados desde la cabeza a los miembros de la estructura político-administrativa hispánica compartían tradiciones y en todos los casos «las autoridades locales y las familias beneméritas se esforzaban por demostrar su lealtad a la Corona»?2.

\section{SANTIAGO DE CHILE Y LA MEMORIA DEL REY DIFUNTO}

Con la muerte de Carlos III desaparecía el monarca que había dado un vuelco sustancial a las relaciones entre la América española y la metrópoli y a la misma configuración interna de los territorios americanos de la Monarquia. El continente americano había experimentado durante su prolongado reinado un auge de conjunto en sus más diversas manifestaciones a la vez que un desarrollo regional traducido en la Capitanía general de Chile en un proceso rápido y concentrado de creación institucional ${ }^{3}$. Asi pues, los actos celebrados en Santiago tuvieron una magnitud acorde a la huella del período carolino y quedaron reflejados en cartas y Relaciones de fiestas que narraban y describian los acontecimientos de duelo colectivo con ocasión de las exequias de un rey tan preocupado por una redefinición de la política indiana.

1 Ejemplo de modelo matizado por la asimilación de la realidad americana meridional: Reales Exequias que por el fallecimiento del Señor Don Carlos III, Rey de España y de las Indias, mandó celebrar en la ciudad de Lima, capital del Perú, el excelentisimo señor Teodoro de Croix, caballero de Croix, del Orden Teutónico, coronel del regimiento de Reales Guardias Walonas, Teniente General de los Reales Exercitos, Virrey Gobernador y Capitán General de las provincias de Perú y Chile, Superintendente General de la Real Hacienda, y Presidente de la Real Audiencia de esta capital. Describialas el reverendo Padre don Juan Rico, presbitero de la Real congregación del Oratorio de San Felipe Neri de Lima, Imprenta Real de los Niños Expósitos, 1789. Archivo General de Indias (A.G.l.), Libros Antiguos, siglo xVIII, 165, Indiferente General, 1608 y Lima, 692. El túmulo limeño de Carlos III en A.G.l., Mapas y Planos, Es-

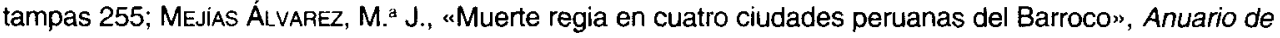
Estudios Americanos, t. XLIX, 1993, pp. 189-205; BÉThEnCOURT MASSIEU, A. de, “Fiestas reales en el Setecientos en Canarias. Identidades, evolución y peculiaridades", Espacio, Tiempo y Forma, Serie IV, H. ${ }^{a}$ Moderna, t. 10, 1997, pp. 263-293.

2 Rodriguez, P., "La vida cotidiana en las ciudades andinas del siglo XVIII", en GARRIDO, M. (Ed.), Historia de América andina, vol. 3, Quito, 2001, p. 241.

3 Castedo, L., "Chile durante el reinado de Carlos III", Cuadernos Hispanoamericanos. Los Complementarios, 2, diciembre 1988, pp. 187-208; BrAvo LIRA, B., "Los Hombres del absolutismo ilustrado en Chile bajo el reinado de Carlos III", en Estudios sobre la época de Carlos III en el reino de Chile, Universidad de Chile, Santiago, 1989, pp. 295-373. 


\subsection{Honrar al rey desde la lealtad: Actos políticos oficiales}

El 21 de julio de 1789 se celebraron en Santiago de Chile las exequias reales por el alma de Carlos III. El escribano mayor de gobierno, justicia, gracia y guerra del reino, Juan Gerónimo de Ugarte, y el escribano público de cabildo y del real cuerpo de minería, Andrés Manuel de Villarreal, certificaron y dieron fe en derecho de la recepción el 28 de marzo del mismo año de un correo que incluía real cédula y órdenes fechadas en Madrid el 24 de diciembre del año anterior participando el nuevo rey Carlos IV la muerte de su padre "con el mas vivo dolor de su filial sentimiento" a la Real audiencia santiaguina y al presidente de ella, muerte que tuvo lugar el día 14 del mismo mes a la una menos cuarto de la mañana; se ordenaba en tales resoluciones que en «todas las ciudades, villas y lugares del distrito de esta gobernación se hiciesen las exequias Funerales, y sufragios, que como duelo Tributo se acostumbra ofrecer por las Animas de nuestros Cathólicos Reyes ${ }^{4}$.

A la recepción del correo se encontraba el presidente Ambrosio Higgins de Vallenar en la villa de Quillota ${ }^{5}$, descansando, de regreso de una visita general a los Partidos septentrionales del reino, «hasta cuios confines, le avia conducido su infatigable zelo". La Real audiencia remitió por acuerdo a Higgins en el día las cédulas y órdenes reales, tras abrir los pliegos y proceder a su lectura. Una vez concluida ufue nezesario conceder algunas treguas al Dolor, que demostraba aquella novilissima Asamblea". Cesado "el ímpetu de la congoja" resolvieron proceder de común acuerdo con el presidente, elaborando y remitiéndole lo que en vista del fiscal se había actuado para que con la mayor brevedad se verificase la expedición de providencias relativas a la publicación de «tan infausta noticia», y de los lutos, pésames y honras de rigor. La Audiencia fue el conducto por el que llegó al capitán general Higgins la noticia de la muerte de Carlos III para que se ejecutaran las honras acostumbradas, el irlandés acusó recibo anunciando que providenciaría todo lo conducente a su cumplimiento, exequias por el monarca fallecido y públicos regocijos por el nuevo rey. Al día siguiente incluyó adjuntos los duplicados de las contestaciones a las reales cédulas en el envío que realizó a Porlier, ministro del Despacho de Indias ${ }^{7}$. El cabildo municipal acusó igualmente haber recibido el duplicado de la real orden que participaba el fallecimiento regio, previniéndole que alzara pendón en honor del nuevo monarca acompañado de demostraciones y solemnidades

${ }^{4}$ A.G.I., Indiferente, 1608. Certificación Relacionada de todo lo que se ha actuado en la celebración de las Exequias Reales, por el Alma de nuestro Difunto Soverano el Sr. Don Carlos $3 .^{\circ}$ que en paz descanse, fechas en Santiago de Chile en 21 de julio de 1789. Santiago, 22 de septiembre de 1789.

${ }^{5}$ ChaUCA GarCiA, J., "Ambrosio O Higgins: paradigma de militar y gobernante en la América meridional del Setecientos", XI Jornadas Nacionaies de Historia Militar. Milicia y Sociedad Ilustrada en España y América (1750-1800), t. I, 2003, pp. 481-499.

${ }^{6}$ A.G.I., Indiferente, 1608. Ambrosio Higgins a Antonio Porlier. Santiago de Chile, 17 de junio de 1789 .

7 A.G.I., Indiferente, 1608. Ambrosio Higgins a Antonio Porlier. Santiago de Chile, 18 de junio de 1789 
acostumbradas para reafirmar «el amor, fidelidad, y lealtad" de la ciudad al Real servicio ; previamente había comunicado el cumplimiento en todas sus partes de la cédula a Antonio Porlier para que lo elevase al rey.

El presidente comunicó de inmediato la «infausta noticia» a los jefes y gobernadores de las plazas de armas para que la anunciasen al pueblo por medio de los tiros y demostraciones que prevenían las ordenanzas militares, además de hacer circular las órdenes a los subdelegados y cabildos de las ciudades y villas del distrito de su mando para que la promulgasen en sus respectivas comarcas "y cumpliesen por su parte con tan justa y cristiana obligación", igual encargo realizó por oficios a los prelados de las comunidades religiosas. Higgins consideraba que «la verdadera demostración de nuestra lealtad y reverente amor al Monarca finado exigía hacer en esta Capital las Exequias con mayor suntuosidad" acorde al fallecido y al ritual subsiguiente al que acudirian las máximas autoridades, por lo que "esta disposición pedía anticipados preparativos y algunas personales agencias". Así, como se había acostumbrado a hacer en casos similares por sus antecesores dio comisión a un ministro de la Real audiencia para que siguiera sus instrucciones en tanto regresaba a Santiago y corría tiempo suficiente para los preparativos, como la construcción del túmulo ${ }^{10}$.

En circunstancias de tanta importancia «los correos parece que volavan", regresando el dia inmediato con la orden de Higgins comunicada al teniente coronel Buenaventura Matute, comandante interino de las Armas, para que «sin perdida de instantes, anunciase al Público el doloroso subceso, por medio de los tiros de cañón», lo que fue ejecutado por la Real audiencia, gobernadora por ausencia del presidente, junto a órdenes encaminadas a que en la Iglesia Catedral y las de los conventos y parroquias se diese idéntico anuncio y se alentasen los ruegos y oraciones de los fieles, con los clamores de las campanas, señalando para tales actos el día 2 de abril desde la Diana por tres días consecutivos. Se procedió a anunciar la "triste nueva» con pregón público solemne.

El día 3 a las once concurrieron a los pésames, que tuvieron lugar en la Real Sala dispuesta con todo el "fúnebre aparato", todos los tribunales, cuerpos militares y órdenes religiosas. Entró el Tribunal de la Real audiencia «a tener en aquel teatro el primer lugar de las congoxas", posteriormente, en orden estricto de prelatura social, comenzaron a entrar el Ayuntamiento de Santiago, la Real universidad, los prelados de las órdenes religiosas, los colegios Real de San Carlos y el seminario, el deán y cabildo eclesiástico, con sede vacante, los cuerpos militares

${ }^{8}$ A.G.I, Indiferente, 1608. El Cabildo, Justicia y Regimiento de la Ciudad de Santiago. Santiago, 20 de junio de 1789.

${ }^{9}$ A G.I, Indiferente, 1608. El Cabildo de Santiago a Antonio Porlier. Santiago de Chile, 3 de marzo de 1789.

10 A.G.I, Indiferente, 1608. Ambrosio Higgins a Antonio Porlier. Santiago de Chile, 23 de septiembre de 1789. Carta del presidente de Chile dando cuenta de las exequias celebradas en la ciudad de Santiago. Acompaña diseño del túmulo y certificación. 
y caballeros de la nobleza principal; representado cada cuerpo social por su cabeza, manifestaron «el profundo sentimiento por la muerte de nuestro Augusto Soverano». Al tiempo el presidente y capitán general "cuio pesar proporcionado a su constante amor y a su justificación, en el servicio de ambas Majestades" providenció que las exequias reales se realizaran con la magnificencia debida al hecho pero evitando caer en lo superfluo como ajeno "de los actos que solo tienen por objeto la Religión". Higgins, además de afrontar la ocasión con espíritu ilustrado manteniendo la dignidad de las exequias fúnebres pero rechazando el excesivo boato barroco en concordancia con la tendencia a reducir gastos de la Corona y las autoridades delegadas indianas ${ }^{11}$, se inclinó al pragmatismo en las tareas de gobierno tomando medidas con prontitud. Mandó que el papel sellado existente en la tesorería real fuese contramarcado con un nuevo timbre "y que la moneda que desde ese día se acuñase, llevara el nombre del nuevo soberano" ${ }^{12}$. Mientras estaba de vuelta en Santiago, en atención a la ejecución de las Reales exequias había comisionado por auto de tres de abril al fiscal del rey don Joaquín Pérez de Uriondo para que dispusiese lo correspondiente y adecuado a celebrar en la catedral, éste aceptó y pidió los expedientes formados al caso para proceder a regular los preparativos y gastos, pero al no encontrarse expediente alguno, consultó a Higgins y con acuerdo de la Junta superior de Real hacienda se resolvió realizar la función fúnebre con la magnificencia posible pero evitando "algunos adornos que no eran precisos" para la idea del arquitecto Joaquín Toesca, mandando igualmente a los ministros de hacienda entregar al fiscal el dinero necesario para el túmulo y demás gastos.

Una vez que se señaló el día 21 de julio para la celebración de las exequias y el comisionado tomó todas las providencias oportunas, mandó Higgins que el dia 20 a las diez de la mañana concurriesen en palacio todos los tribunales, cabildos, universidad, colegios, militares y religiosos, y la nobleza para cumplimentar el pésame, y que desde aquella misma hora comenzase el doble de campanas en todas la iglesias para despertar la piedad de los fieles a rezar por el alma del rey, al tiempo que se iniciasen los tiros de artillería ${ }^{13}$; pasándose los oficios correspondientes a los prelados de las órdenes religiosas para que asistieran con sus respectivas comunidades a los oficios de difuntos, a Vísperas, en la Iglesia Catedral, y el 21 hasta concluirse las honras.

"Muestra de austeridad la encontramos en la proclamación de Felipe V en San Francisco de Quito, vid. Archivo Metropolitano de Historia de Quito, Sección Secretaría General, Serie Actas del Consejo, 1699-1704, cit por ALFonso MOLA. M., "Fiestas en honor de un Rey lejano. La proclamación de Felipe V en América", en Felipe $V$ y el Attánticc. III Centenario del Advenimiento de los Borbones, Ediciones del Cabildo de Gran Canaria, Las Palmas, 2002, pp. 249-308 (Nota 44, p. 266). Sin duda la posición periférica de Santiago, al igual que Quito, en relación a Lima llevó a celebraciones necesariamente más austeras comparativamente con la capital virreinal, no obstante la entidad alcanzada evidenció el importante crecimiento chileno a io largo de la centuria.

12 Barros ARAnA, D., Historia General de Chile, t. VII, Editorial Universitaria/Centro de Investigaciones Diego Barros Arana, Santiago de Chile, 2001, p. 31.

13 Conforme al Artículo Primero, Título Quinto, Tratado Tercero de las Ordenanzas del Ejército. 
La sala se dispuso con todo el aparato al caso en tales ceremonias, en una atmósfera que resultaba

«incentibo a la Retórica, que en su lugubrez, podía descubrir mudamente la maior triste melancolía, y excesiva demostración del sentimiento del noble corazón de aquel Gefe herido con el fallecimiento de tan Augusto Monarcas ${ }^{14}$.

Dada la señal pertinente a las diez de la mañana del día 20 entró en la sala la Real audiencia lievando el séquito correspondiente a su autoridad, con el tribunal de Cuentas y superintendencia de la Real Casa de Moneda; seguidamente tomó la palabra el oidor decano don Francisco Tadeo Díez de Medina expresando con «facundo estilo y palabras de gran peso" el profundo sentimiento de la institución que representaba, necesitada de consuelo, que le venía de la esperanza de premio divino al soberano por las «justas intenciones con que prosperó su feliz Reinado». A continuación el Ayuntamiento santiaguino por quien habló el subdelegado Melchor de la Xaraquemada, "demostrando con mui sentidas expreciones el dolor del fallecimiento" del rey a quien la capital chilena debía tantos monumentos obrados merced a su «real generosidad". Posteriormente entró la Real universidad que por su rector el Dr. José Santiago Rodríguez explicó el pesar del mundo de la sabiduria a quien el monarca "había colocada con tanto honor de la nación en San Felipe el Real de esta ciudad dando tantos alumnos a Minerva" que en breve conformarian una «corte de savios". Luego sucedieron en el pésame y tributo póstumo los prelados de las ordenes religiosas, quienes declararon el sentimiento de dolor por la pérdida de un soberano «el más zeloso Patrón, y vigilante Protector del estado Religioso", ofreciendo la copia de sus oraciones y sufragios. Después entraron los colegios, el Real de San Carlos y el seminario, manifestando sus respectivos rectores el pésame y angustia por la muerte de un monarca gracias a cuya «apacible sombra, y zelo, fueron ambos colegios fértiles jardines de la ciencia». Más tarde entró el deán y cabildo, sede vacante, dando el pésame el arcediano Dr. Juan de los Ríos y Terán, quien además manifestó el sentimiento por la pérdida de un rey "tan pio, y justo, a quien devió esta Catedral los más singulares favores de su liberalidad». Finalizó el acto la milicia y toda nobleza de la ciudad «entrando cada uno en el lugar que lograva en el gran concurso" y expresando el dolor y pesar por la muerte de un soberano que fue «tan amante de sus vasallos» ${ }^{15}$.

\subsection{Celebraciones religiosas: Túmulo catedralicio}

Cuestión aparte y completando la cuidada escenografía regia e iconografía funeraria lo constituye el túmulo ${ }^{16}$, elemento central de atención, arquitectura efíme-

14 A.G.I., Indiferente, 1608. Certificación Relacionada...

15 Ibídem.

16 Podemos establecer un paralelismo entre Santiago de Chile y Santiago de Guatemala, pues si bien las exequias reales se celebraban en varias localidades, en las capitanias chilena y guatemalteca 
ra dedicada a la memoria del rey difunto, que se colocó sobre el presbiterio de la catedral, con estructura proporcionada a las dimensiones de la misma y con un "estilo serio sin cargarle ni confundirlo de adomos inpropios, cuia causa aumentara su ermosura" basada precisamente en los parámetros clásicos de sencillez decorativa, equilibrio y proporción ${ }^{17}$; respecto a las dimensiones eran de 36 pies de latitud por 40 de longitud, siendo la elevación total de la iglesia de 60 pies $^{18}$. De planta rectangular y dos cuerpos, formaba en el frente principal dos rampas laterales de escaleras que desembocaban en un descanso común para la entrada del primer cuerpo a modo de tránsito de la vida a la muerte ${ }^{19}$, en cuya puerta se situaba una figura alegórica de la Muerte que mantenía con las manos el manto real en acto de llevárselo, en clara alusión al poder de la muerte sobre la gloria terrenal, y al mismo tiempo hacía de cortina. La escalera estaba adornada de una barandilla corrida con balaustrada delicada y cuatro pedestales, cada uno mantenía una estatua, imágenes que representaban a las Virtudes cardinales: la Justicia, la Prudencia, la Fortaleza y la Templanza; simbolizando las virtudes del Príncipe y el buen gobierno de un rey preocupado por sus súbditos aun de tan remotos confines ${ }^{20}$.

El primer cuerpo, zócalo del segundo, estaba repartido con diferentes pilastras que mantenian sobre su cornisón una barandilla corrida de balaustres con sus correspondientes pedestales, sobre los que descansaban unas hermosas pirámides sepulcrales cubiertas de luces, y entre una y otra se elevaban cuatro figuras de virtudes, en armonia con las inferiores, de la Caridad, la Piedad, la Mansedumbre y la Clemencia ${ }^{21}$. Sobre este piso, en distancia de vara y media de dicha barandilla, se elevaba un zócalo de dos varas de alto sobre el que descansaban los plintos de las

eran sus capitales donde manifestaban mayor ostentación como podemos ver en sus respectivos túmulos de estilo neoclásico y con iconografía alusiva al triunto de la muerte y el poder la monarquía. Vid. BERLIN, H. y LuJAN MUÑoz, J., Los túmulos funerarios en Guatemala, Academia de Geografía e Historia, Guatemala, 1983. Grabado y descripción del túmulo carolino en pp. 54-62; Sото CABA, V., Catafalcos reales del Barroco español. Un estudio de arquitectura efímera, UNED, Valladolid, 1992.

17 Guarda Gerwitz, G., "El triunfo del Neoclasicismo en el Reino de Chile", Boletín del Centro de Investigaciones Históricas y Estéticas, n. ${ }^{\circ} 8,1967, \mathrm{pp} .9$ 9-31; BENAvides COURTOIS, J., «Arquitectura e ingeniería en la época de Carlos III. Un legado de la llustración a la capitanía general de Chile", en Estudios sobre..., pp. 79-170; IgLESIAS, A. y PORTE, E., La Catedral de Santiago de Chile, Universidad de Chile, Santiago, 1955; De RAMÓN, E., Obra y fe. La catedral de Santiago 1541-1769, DIBAM/CIDBALOM, Santiago, 2002.

${ }^{18}$ El "pie», del latín pes, era una uridad de medida romana que equivale a $0,2957 \mathrm{~m}$. (casi $1 / 3$ de metro); la latitud ( $N-S$ ) y la longitud (E-O). Así, los 36 pies de latitud: $10,65 \mathrm{~m}$. de altura; los 40 de longitud: $11,83 \mathrm{~m}$. de base; aspecto impresionante en relación con los 60 pies de la iglesia en altura: $17,74 \mathrm{~m}$.

19 Mejias Álvarez, M. a J., Fiesta y muerte regia: Las estampas de túmulos reales del AGJ, CSIC/EEFHA, Sevilla, 2002, p. 71. Otras descripciones en MORALES Folguera, J. M., "Los túmulos funerarios de Carlos III y la imagen del rey en Hispanoamérica y Filipinas", Boletín de Arte, n. ${ }^{\circ}$ 9, 1988, pp. 135-158 (p. 142); Ramos SoSA, R., “Los túmulos de Carlos III en Hispanoamérica: México, Lima, Santiago de Chile y Valparaiso", Cuadernos de Arte Colonial, n. ${ }^{\circ} 6,1990$, pp. 33-51 (pp. 40-45).

20 VALBERT, C., La iconografía simbólica en el arte barroco de Latinoamérica, La Paz, 1987; SCHENONE, H., Iconografia del arte colonial, Fundación Tarea, Buenos Aires, 1992.

${ }_{21}$ Estas virtudes que complementan las propias del soberano están constatadas por escrito en la $R e-$ lación, sin aparecer en el dibujo; representan las cualidades o atributos del monarca finado y su reinado. 


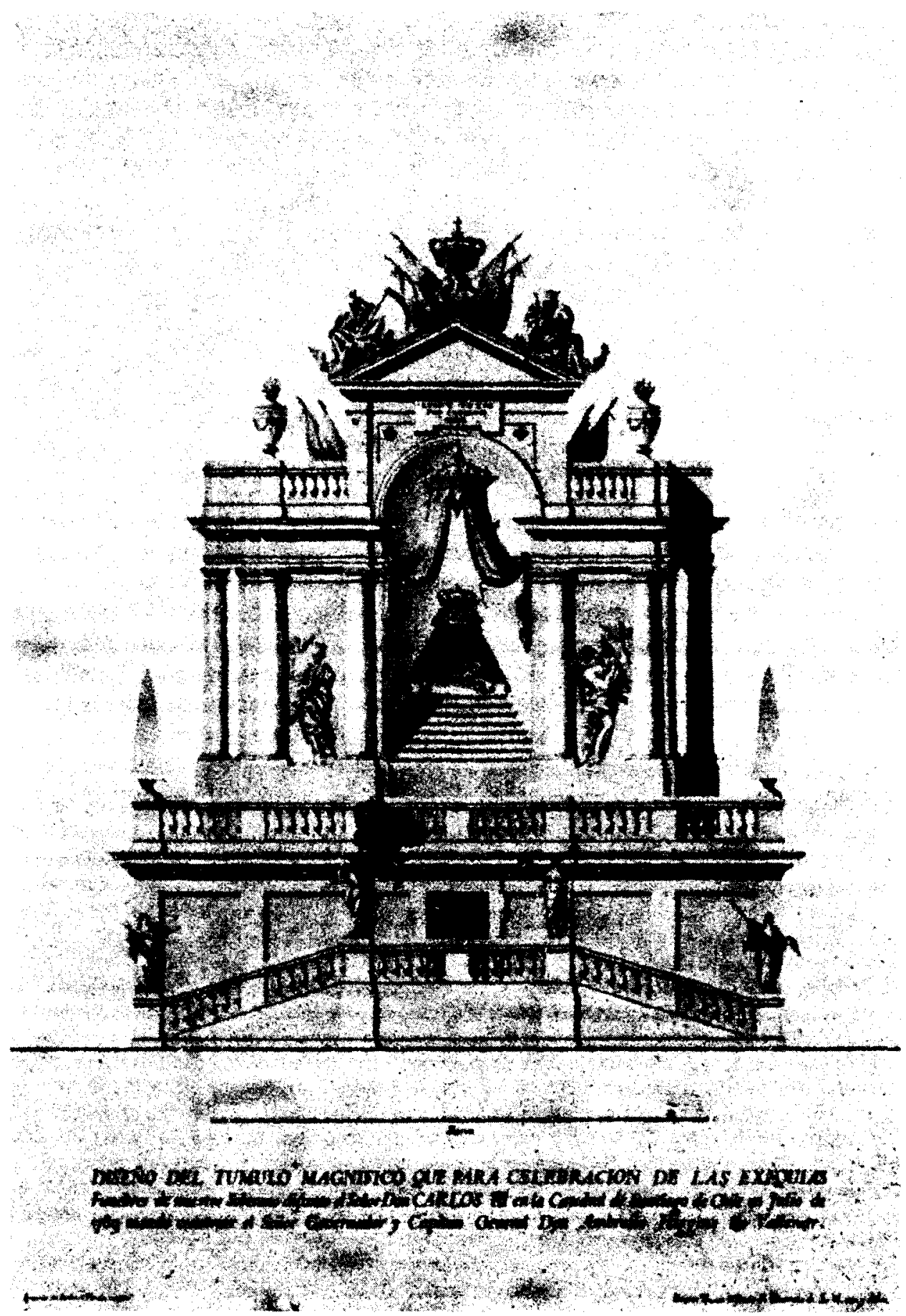

Túmulo de Carlos III en Santiago de Chile. A.G.I. Mapas y Planos. Perú y Chile, 117. 
seis columnas dóricas con sus capiteles, friso y cornisa, el segundo cuerpo, y entre las dos columnas centrales se formaba un arco de medio punto que daba entrada a un camarín en medio del cual sobre una escalinata de ocho gradas se colocó la tumba o el sitial real cubierto de terciopelo negro con unas ricas franjas de oro con su corona, cetro y espada, atributos de la dignidad real; y en los intercolumnios, flanqueándolo otras dos figuras representando alegóricamente a la Muerte y al Tiempo, la primera con las insignias reales, lo efímero de las glorias terrenas, y la segunda como un Saturno maduro y alado, ambas con reloj de arena que simboliza inequívocamente la fugacidad vital. Sobre el cornisón corría otra barandilla abalaustrada cuyas pilastritas correspondian perpendicularmente en los diámetros de las columnas inferiores y mantenían unas grandes jarras o urnas sepulcrales.

El cuerpo superior formaba un ático con sus pilastras y medias pilastras, en cuyo extremo corría una cornisa arquitrabada que remataba en un frontón triangular. Debajo de éste resaltaba una tarjeta en la que se leía «Luget Totus pro Carolo tertio orbis" 22 . En los dos ángulos del frontón estaban sentadas dos Muertes, una con guadaña en la mano y la otra con el cetro real, y en medio de ambas, en el ángulo superior, un Niño desnudo entre trofeos de guerra ejemplarizantes de las victorias del rey fallecido y banderas, que sostenía con las manos la Corona $\mathrm{Real}^{23}$. El afamando arquitecto y discípulo de Francisco Sabatini que confeccionó el diseño y dirigió la construcción del túmulo, Joaquin Toesca y Ricci, «medió en la obra la gigante estatura del objeto a quien se dedicó", dentro de los cánones neoclásicos $^{24}$. Bajo su dirección trabajaron artesanos como Pedro José de Mena, Marcos Fuenzalida, Marcos Hurtado y Antonio Ribas, con maestría demostrada como carpinteros, pintores o en las labores de platería ${ }^{25}$.

En la nave central de la iglesia se pusieron 22 arañas de plata con sus correspondientes bujías que iluminaban la suntuosidad del espectáculo. Los pilares se cubrieron de paños negros y en ellos se colgaron 46 tarjetas doradas de colores matizados con variadas poesías «en diferentes metros que explicavan el sentimiento por la muerte del Monarca». Distribuidos 30 hacheros de los que al pie de 24 de sus hachas un escudo con los blasones de Armas de cada uno de los reinos de los dominios españoles, empezando por los de Castilla, León y Aragón testimoniaban «el justo sentimiento por su Duer̃o». De los cuatro púlpitos de la Iglesia colgaban paños negros en señal de luto de la misma calidad que las columnas y encima de terciopelo negro con galones de oro, y en el principal, donde se tenía que decir el

22 «El Orbe entero llora por Carlos III».

23 A.G.l., Mapas y Planos, Perú y Chile 117. Diseño de túmulo para las exequias de Carlos III en la Catedrai de Santiago de Chile. Adjunta un dibujo del Mausoleo debido a José Ignacio Andía y Varela. Vid. Angulo ínIGUez, D., Planos y documentos arquitectónicos de América y Filipinas del Archivo General de Indias, Sevilla, 1933, 7 vols. Lámina 226. Estudios II, p. 516.

24 Guarda, G., El arquitecto de la Moneda, Joaquín Toesca 1752-1799: Una imagen del imperio español en América, Ediciones Universidad Católica de Chile, Santiago, 1997.

25 Pereira Salas, E., Historia del Arte en el Reino de Chile, Santiago de Chile, 1965, pp. 192-193. Cit. por Ramos Sosa, R., "Los túmulos...", p. 51 (Nota 29). 
panegírico fúnebre, se colocó el escudo de las Armas Reales, mientras que en su frente se situó el de la ciudad de Santiago, testimonio y licencia de identidad.

El magnífico túmulo aparentaba envolver con las llamas de la multitud de velas de cera del norte todo el templo, por lo que se dispusieron cuatro hombres repartidos y prevenidos con agua para apagar prontamente un posible y temido incendio; en correspondencia con el luminoso cenotafio en la Iglesia ardían «un sin número de luzes a la Inmortal memoria de la Majestad Divina ${ }^{26}$.

Una vez preparado el real mausoleo se dio principio a los solemnes maitines de difuntos la tarde del día 20; a las once de la mañana comenzaron los clamores y dobles de todas las torres, al igual que el estruendo de la salva real de artillería, con una repetición de cuarto en cuarto de hora. $A$ las tres de la tarde, las tropas militares acamparon dispuestas en dos alas que comunicaban el palacio con la catedral, ejes de la liturgia cívico-religiosa ${ }^{27}$, "con el aspecto de tristeza que correspondía a aquella asistencia funesta»; una hora después salió del palacio el presidente Higgins con toda la comitiva de duelo compuesta por el tribunal de la Real audiencia, el de Cuentas y superintendencia de la Real Casa de Moneda, al ayuntamiento de la capital, la Real universidad, y toda la nobleza, y una vez llegaron a la catedral se situaron en sus respectivos lugares dando comienzo al compás de música el oficio de difuntos; cantó la última oración en laúdes el arcediano Dr. Juan de los Ríos y Terán, concluyendo con un responso con cera en mano todo el clero y órdenes religiosas, con lo que se dio por finalizada esta función.

Al día siguiente a las diez de la mañana, puestas las tropas en el mismo lugar y orden que en la tarde anterior, salió el presidente con igual acompañamiento, entrando en la Iglesia y sentándose; encendido el túmulo empezó la solemne misa el arcediano, y concluida subió al púlpito el Dr. José Antonio de Errazuriz, canónigo doctoral, quien dijo una oración "con la maior ternura, y general aceptación». Acabada, se repartieron las velas al clero secular y regular, y puestos en pie todos los participantes entonó el coro con música cinco responsos cantados por cada una de las dignidades y se finalizó la función fúnebre con el Requiem cat in pace.

Higgins dio cuenta al nuevo soberano Carlos IV mediante puntual certificación de lo ejecutado durante las exequias fúnebres celebradas en Santiago acompañada del diseño del túmulo regio formado en la catedral, que satisfizo al monarca por el cumplimiento que providenció a la Real cédula que comunicaba el fallecimiento de Carlos III y disponía las demostraciones acostumbrados en semejantes $\operatorname{casos}^{28}$.

${ }^{26}$ A.G.I., Indiferente, 1608. Certificación Relacionada.

27 VALENZUELA MÁRQUEZ, J., Las liturgias del poder. Celebraciones públicas y estrategias persuasivas en Chile colonial (1609-1709), DIBAM/CIDBA, Santiago de Chile, 2001, p. 31.

28 A.G.l., Indiferente, 1608. Al Señor Presidente de Chile. Madrid, 23 de marzo de 1790. Se hacia presente a Higgins dos días después, como contestación a la recepción el 23 de septiembre último participando lo celebrado en orden a las exequias reales, la satisfacción del rey una vez informado por Antonio Porlier. 


\subsection{Regulares y derrama de lutos por la ciudad}

Los actos fúnebres principales por Carlos III fueron acompañados con posterioridad por una serie de funerales públicos consecutivos, diseminados por la ciudad, en los que los prelados de las órdenes religiosas se esmeraron y rivalizaron en honrar al difunto monarca, "desempeñando esta obligación con la magnificencia posible». El provincial del orden de predicadores de la Provincia de San Lorenzo Mártir de Chile, avisó del recibo de las ordenes regias quedando "en executar exactamente quanto en ella se ordena", es decir, funerales en los conventos previa comunicación con las autoridades; insuflando su respuesta de promesas de prontitud y amor al real servicio "tan característico de mi Sagrada Religión, como que queda grandemente consternada con tamaño golpe, trascendental a toda la Monarchia ${ }^{29}$. La orden celebró función fúnebre el 29 de julio, con la asistencia del presidente, tribunal de la audiencia, ayuntamiento de Santiago y muchos "vecinos distinguidos"; ejerció de orador el padre Fray Juan José González.

El provincial de la Merced de la Provincia de Chile acusó el recibo de la orden y cédula mandando realizar honras, exequias y sufragios, actuando de acuerdo con el presidente y audiencia para avisar a todos los conventos y proceder "quanto antes... por el alma de tan piadoso y benigno Soberano ${ }^{30}$. El día siete de agosto le tocó el turno a los mercedarios, con igual demostración y asistencia, siendo el protagonista de la oración fúnebre Fr. Joaquín Larrain.

El provincial de San Francisco de la Provincia de Chile avisó haber mandado, comunicada por circular, y hecho las exequias y sufragios por el alma de Carlos III. El día ocho de agosto fue el turno de la orden seráfica con repetida asistencia y contando como predicador con Fr. Manuel Díaz. Los lazos de amistad, sintonía y colaboración entre Higgins y la orden de San Francisco se tradujeron en un estricto cumplimiento de los mandatos reales, dejando incluso constancia por escrito de la exaltación del monarca difunto y los mejores augurios para el nuevo rey, en línea con la fidelidad del presidente por el Borbón ilustrado y su estrecha relación con los franciscanos como sustitutivos de los jesuitas en las fronteras indianas. El provincial franciscano de la Provincia de la Santísima Trinidad del Reino de Chile, Fray Thadeo Boza, "transpasado de un verdadero sentimiento" por la muerte del rey realizó las exequias pertinentes y pasó informe de ellas a Carlos IV quedando como «fiel, y agradecido vasallo de tan gran Monarca continuando sus oraciones, sin perder de vista a V. M." para quien pedía fortaleza y conformidad en tales momentos al tiempo que "vida mui dilatada para que se puedan templar en algún modo los justos sentimientos de estos sus amantes vasallos" y procurar el bien que la

${ }^{29}$ A.G.I, Indiferente, 1608. El Provincial de los Predicadores a Antonio Porlier. Santiago de Chile, 4 de abril de 1789.

${ }^{30}$ A.G.I, Indiferente, 1608. El Provincial de los Mercedarios a Antcnio Porlier. Santiago de Chile, 29 de marzo de 1789. 
"Monarquía desea y necessita» ${ }^{31}$. Previamente había transmitido a todos los reverendos padres guardianes y demás religiosos la Real cédula que comunicaba el óbito de Carlos III a fin de que se celebraran en todos los conventos de la orden de esa provincia las honras y exequias pertinentes que el rey Carlos IV fiaba en "vuestro celo y amor a mi real servicio", en común acuerdo con el presidente y la audiencia; igualmente constataba haber recibido carta orden del capitán general, por lo que se hallaban «en la obligación de cumplir con nuestro deber» de oraciones y vasallaje acentuado por la

«particular obligación que nos asiste de agradecidos por los especiales favores con que honrró a nuestra Religión tan piadoso Monarca, y la especial devoción, que a ella tuvo honrrandola con ceñir nuestra cuerda de hermano tercero Professo»32.

Por todo lo cual mandaba a los padres guardianes y religiosos que en los conventos se hiciera un aniversario con toda la solemnidad posible contándose Vísperas y Maitines de difuntos con su misa y predicación, ofreciéndose por el alma del rey fallecido; además, los que no fuesen sacerdotes debian comulgar ese día, y los legos debían rezar cien padrenuestros con requiem eternam. Asimismo tendrían todos presentes en sus oraciones y rogativas a Dios el aima del monarca. De su ejecución darían aviso los guardianes «para lo qual correran estas nuestras letras de convento en convento" por orden señalado «haciéndose leer en plena comunidad a son de campana como es costumbre". Estas medidas fueron determinadas en el convento Grande de Nuestra Señora del Socorro de la ciudad de Santiago por el provincial Fray Thadeo Boza, actuando como secretario Fr. Manuel Díaz ${ }^{33}$.

El provincial de los agustinos, Fr. Thomas Donoso Pajuelo, avisó el 4 de abril de 1789 el recibo de la orden de 24 de diciembre pasado sobre exequias y funerales oficios a realizar en sus conventos, acompañada de Real cédula participando la noticia del fallecimiento, ante lo que afirmaba "executaremos con la mayor brevedad, como feudo de nuestra obediencia, y filial amor, por tantos títulos devidos a Nuestros Soberanos" ${ }^{34}$. Finalmente el 17 de agosto la orden de San Agustín concluyó el ciclo de celebraciones con idéntica asistencia que las anteriores, ejercitando de orador el padre lector Fr. José de Lazarte. Nota común a todos los oradores, como no podía ser menos, fue «la más fina explicación de las virtudes de nuestro difunto Monarca". Todos los prelados contestaron al presidente los oficios

31 A.G.I, Iridiferente, 1608. El Provincial de los Franciscanos a Carlos IV. Santiago de Chile, 13 de agosto de 1789.

${ }^{32}$ A.G.I, Indiferente, 1608. Fr. Thadeo Boza, comisario provincial franciscano, a los Padres Reverendos de su orden. Santiago de Chile, 7 de marzo de 1789.

${ }^{33} \mathrm{lbidem}$. La ermita del Socorro custodiaba una imagen de la Virgen traida por el conquistador-fundador Pedro de Valdivia, encomendada en un principio a los frailes mercedarios pasó en 1554 a los franciscanos, llegados a Chile el año anterior.

${ }^{34}$ A.G.I. Indiferente, 1608. El Provincial de los Agustinos a Antonio Porlier. Santiago de Chile, 4 de abril de 1789 . 
que les pasó informándoles la noticia, al tiempo que ofrecieron los ruegos y oraciones de sus comunidades por el alma del fallecido rey "como consta de sus originales en el expediente de la materia ${ }^{35}$. Según el propio Higgins se celebraron "con gran lucimiento, concurso, y ostentación de la Majestad difunta, sin exceso de gastos", habiéndose observado "exactamente Su Soberana Voluntad en asunto tan importante a Su Real Servicio " ${ }^{36}$.

Constaba también en expediente haberse circulado y comunicado a todos los gobernadores, comandantes y subdelegados del reino la noticia "para que cada uno por su parte cumpla, y haga cumplir con las demostraciones de Fieles Vasallos", en línea con evitar los excesos y vanidad en unos actos que "solo deven tener por obgeto la Religión» y una sincera manifestación de la fidelidad real, teniendo presente las leyes y costumbres al caso; además los empleados en el senvicio del rey, regidores y vecinos y vasailos de distinción de las ciudades, villas y lugares debían tomar, a su costa, riguroso luto hasta el día de las exequias y de ahí en adelante aliviado, por el término de seis meses contados desde el tres de abril de 1789. Para velar por su observancia efectiva se remitieron los correspondientes testimonios del edicto proveído en la villa de San Martín de Quillota para que una vez publicado "en la forma acostumbrada de vando ninguno alegase ignorancia». Según el ceremonial de 1760 , el traje de los capitulares en luto de personas reales debía ser todo de lanilla negra en período riguroso, posteriormente, en el medio luto llevarían sólo la chupa de tafetán doble ${ }^{37}$.

En cumplimiento de lo mandado por superior decreto de siete de septiembre, al margen del oficio, el fiscal don Joaquín Pérez de Uriondo y Martiarena, como comisionado, pasó al presidente una relación prolija de todo lo obrado en la que manifestó «el más vigilante Zelo, Amor, y lealtad a nuestro Soverano", sin dispensar la suntuosidad que permite la catedral pero respetando "los límites de los gastos mui precisos, como celoso ministro, en guardar y observar las Reales Disposiciones ${ }^{38}$. La Audiencia de Santiago comunicó al rey en su Real y Supremo Consejo de Indias que se habían practicado las diligencias que manifestaban los testimonios adjuntos ${ }^{39}$.

Los actos celebrados en Santiago tuvieron dos fases, una central y primera en el palacio del capitán general, consistente en un pésame de las autoridades civiles, religiosas y militares del reino, con demostración pública de dolor y exaltación del monarca fallecido y lealtad a la institución monárquica, en un abigarrado desfile de

${ }^{35}$ A.G.I., Indiferente, 1608. Certificación Relacionada...

${ }^{36}$ A.G.I., Indiferente, 1608. Ambrosio Higgins a Antonio Porlier. Santiago de Chile, 23 de septiembre de 1789 .

${ }_{37}$ Tabla de las seremonias que observa el llustre Cabildo en todas sus funciones, asi públicas como secretas, cit. en AlEMPARTE, J., El cabildo en Chile colonial, Ediciones de la Universidad de Chile, Santiago, 1940, pp. 292-293.

38 A.G.I., Indiferente, 1608. Centificación Relacionada...

${ }^{39}$ A.G.I., Indiferente, 1608. Real Audiencia de Santiago a Antonio Porlier. Santiago, 4 de abril de 1789 
representantes de ambos poderes, político-militar y eclesiástico, y nobles no exento de una marcada jerarquización en su presentación social; asociada a esta visualización colectiva de fidelidades, las celebraciones sacras por el alma del rey se acompañaron de idénticas estratificaciones junto a una liturgia del poder de la monarquía acompañada del recordatorio de lo fugaz terrenal, en perfecta simbiosis. En una segunda fase estas demostraciones pasaron a diseminarse por la ciudad, se comunicó al estamento eclesiástico la noticia para que celebraran diversos actos religiosos las órdenes regulares asentadas en Santiago, ratificando de nuevo el compromiso con la continuidad institucional y dejando huella en la memoria colectiva.

\section{VALPARAIISO RECUERDA AL REY: MÉRITOS Y SERVICIO REAL}

La capital del reino de Chile no fue en exclusiva escenario de la ritualización de confirmación de la condición de vasallos de un rey distante al tiempo que presente en retratos y estandartes reales, sino que se extendió por el territorio de la jurisdicción chilena, diseminada por sus iglesias.

El gobernador de Valparaíso Josef Salvador hizo presente que careciendo la ciudad de fondos para sufragar los gastos públicos para las celebraciones debidas por la muerte del monarca, costeó personalmente los ocasionados por las exequias fúnebres celebradas en dicha ciudad el 20 de julio de 1789, con «la decenzia que fue posible» en cumplimiento de la orden de 24 de diciembre de 1788, remitiendo el diseño del túmulo que se formó en la Iglesia matriz de Valparaíso ${ }^{40}$. Añadía que además de cercenar de sus cortas rentas cuanto podia «en atención a la falta de fondos con que se hallaba dicha ciudad determinó fabricar una Recoba, donde se vendiesen toda suerte de comestibles con arreglo a Aranzel» de un real por carga, igual que se exigía anteriormente a los dueños de los corredores donde se acogían a vender sus efectos; gastó en esta construcción mil seiscientos pesos con el fin de dejar esta renta en beneficio de la ciudad una vez reembolsado el dinero que puso. El primer año se obtuvieron seiscientos pesos, pero desgraciadamente «antes de integrarsse en la sobre dicha cantidad y restandole aun ochocientos pessos, destruió un recio temporal la mencionada Recoba", no obstante, a pesar del contratiempo en el proyecto se prosiguió "practicando vivas diligencias para su remedio hasta su total reparazión", concluyendo con la súplica al rey para que «tenga a bien admitir este corto merito". Se dio acuse de recibo de la carta que el 10 de agosto de 1789 habia mandado el gobernador a Antonio Porlier, quedando enterado el rey de lo practicado en la celebración de las exequias reales por el alma de su padre en cumplimiento de la Real orden de 24 de diciembre del año anterior ${ }^{41}$.

40 A.G.I., Mapas y Planos, Perú y Chile 118. Plano del Túmulo que se formó en la Iglesia matriz de la ciudad de Valparaíso por las exequias de Don Carlos III.

41 A.G.I., Indiferente, 1608. Antonio Portier al gobernador de Valparaiso. Madrid, 16 de marzo de 1790. Se contestó el recibo y la confirmación de quedar enterado el rey con fecha 11 de marzo y se comunicó cinco dias después. 

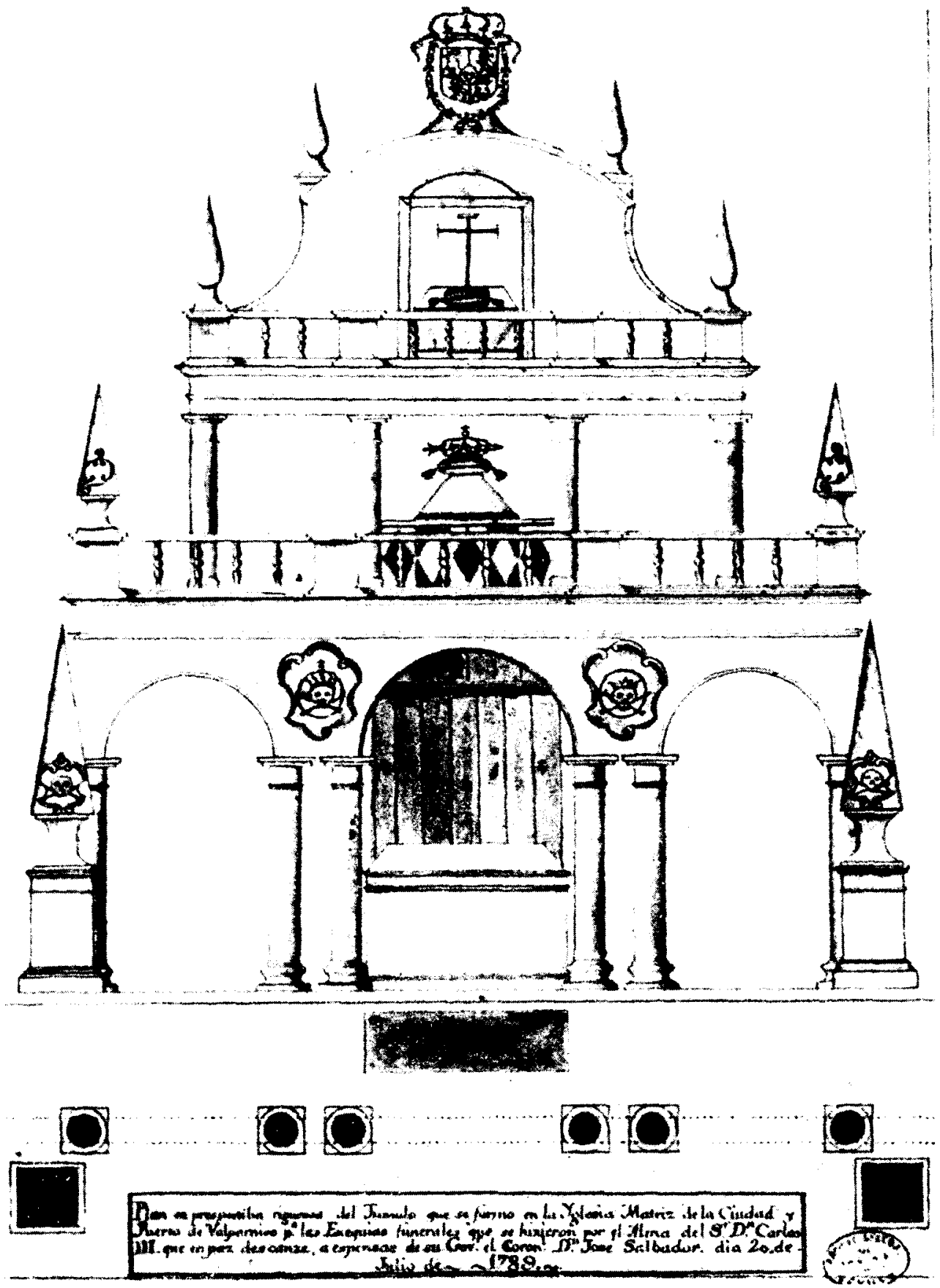

Túmulo de Carlos III en Valparaíso. A.G.I. Mapas y Planos. Perú y Chile, 113. 
El gobernador de aquel remoto puerto de la Monarquia aprovechó la circunstancia para ofrecer un servicio del que esperaba obtener algún tipo de compensación política en premio a su lealtad y celo a la Corona, por supuesto debía comunicar sus méritos a Madrid de forma relacionada y esperar la promoción. Así, expresaba que desde que alcanzó el gobierno de Valparaíso había «propendido en el adelantamiento de esta ciudad, que (sin elogio proprio) estaba mui a los principios». Su atención prioritaria se dirigió a adjudicar a la ciudad fondos «pues ningun Pueblo las nesecita mas que este por su cituazión y que era impocible conseguirlo por falta de caudal» motivo por el que construyó la recova citada, pero

«el día 28 de junio del año próximo pasado en un furioso temporal la destruyese enteramente la havenida de un Estero, que no caviendo en sus causes, rebosó por encima de los puentes (que si hubiera proseguido aquella especie de dilubio hubiera arruinado mucha parte de la ciudad) bolvimos a quedar como al principio, y en la misma inagción por falta de fondo" ${ }^{42}$.

No obstante, la desgracia no pudo con el ánimo del gobernador que hace un alarde de determinación y constancia, señalando sus esfuerzos para el «adelantamiento de esta plaza". La ciudad había quedado sin Propios cuando llegó la noticia del fallecimiento de Carlos III por lo que el gobernador consultó a la capitanía general qué ramo debía soportar los gastos ocasionados por las exequias, recibiendo por respuesta que «me arreglara a la costumbre», pero resultó que era la primera vez que se iban a celebrar tales demostraciones bien «por falta de fondos o por no haverlo solicitado mis Antecesores» por lo que deliberó «estimulado de mi cincero Amor, y entero reconocimiento a un soverano que tanto le he merecido" realizando a sus expensas la función fúnebre con el mayor lucimiento posible respetando la Real orden sobre moderación. Prometió actuar igual con motivo de las fiestas reales de proclamación «por alentar a estos basallos al amor, veneración y fidelidad, que deven profezar a nuestro Soverano", máxime en "estos remotos Paizes, en donde mas se nesecita hacerles conocer esta obligación". Por último, solicitó la "poderosa Protexión" del destinatario de su carta-informe acorde a su mérito y lealtad demostrada con la iniciativa y financiación de las honras ${ }^{43}$.

El puerto de Valparaíso levantó por primera vez un túmulo funerario de inspiración clasicista y limitadas ambiciones, costeado por su gobernador el coronel José Salvador ${ }^{44}$. Se componía de dos cuerpos con remate, el primero presenta tres arcos de medio punto que descansan sobre seis columnas, pareadas las cuatro centrales, encima de las cuales, sobre los intercolumnios, en dos tarjas, calaveras con dos tibias cruzadas al igual que en las pirámides del primer cuerpo pero con corona que simbolizan al rey fallecido, rematado con balaustrada corrida en cuyos extremos se sitúan pilonos sobre pedestales que se repiten en gradación de tamaño de mayor a

42 A.G.I., Indiferente, 1608. José Salvador a Antonio Porlier. Valparaíso, 10 de agosto de 1789.

43 Ibidem.

44 Para la descripción del túmulo vid. Angulo íñIGUEZ, D., Op. cit., Lámina 227, Estudios II, p. 518; MoRAles Folguera, J. M., “Los túmulos funerarios...», p. 144; Ramos SOSA, R., "Los túmulos...”, p. 46. 
menor del zócalo al remate, con decoración de calaveras en las inferiores; bajo el arco central se encontraba un discreto altar. El siguiente cuerpo del artefacto estaba compuesto por cuatro columnas que soportaban estructuralmente el entablamento, coronado igualmente por balaustrada, entre las dos columnas centrales se situaban los símbolos reales, corona y cetro, sobre cojín encima de plataforma, exaltando la monarquía a pesar del triunfo de la muerte sobre lo terrenal en el nivel inferior iconográfico. Sobre el segundo cuerpo descansaba un frontón de perfil cóncavo-convexo, con una cruz en medio sobre cojín, simbolizando la victoria de Cristo sobre la muerte y abriendo paso a la esperanza de la resurrección ${ }^{45}$. Coronando el conjunto y presidiéndolo junto a la Cruz, situado en su vertical, el escudo del rey con las Armas de Castilla, en perfecta unión de Trono y Altar.

A diferencia del autor del túmulo santiaguino, en este caso debió tratarse de un artista local en orden a la simplicidad estilística del monumento funerario. Comparte la arquitectura efímera en su distribución vertical e iconográfica el tema del triunfo de la muerte sobre las glorias terrenas, de larga tradición hispánica, y la exaltación de la monarquía ${ }^{46}$.

La muerte del monarca, 14 de diciembre de 1788, fue comunicada por Orden y Real Cédula de 24 de diciembre del mismo año, es decir diez dias después, tardando tres meses en atravesar el Atlántico y llegar al Pacífico sur americano, recibida con fecha 28 de marzo de 1789; así, entre la recepción de la noticia del fallecimiento del rey y la celebración de las exequias en Santiago de Chile, el 21 de julio del mismo año, transcurrió un lapso de tiempo cercano a los cuatro meses. En total, entre el óbito del soberano y las exequias santiaguinas mediaron algo más de siete meses, dato revelador de los tiempos y el factor distancia en el sistema de comunicaciones de la Monarquía, tratándose de un confín territorial de la estructura hispánica ${ }^{47}$. Las exequias en Valparaíso se adelantaron un día a Santiago, su naturaleza portuaria, mayor simplicidad de actos y del túmulo erigido y el deseo de obtener méritos de su gobernador pueden explicar este hecho. Por último en esta derrama de noticias, se hacían diversos traslados o copias de las órdenes y cédulas reales a instituciones, regulares y localidades, de las que daban acuse de recibo y acatamiento en orden a celebrar con dignidad las exequias y proceder a la proclamación del nuevo rey. Las noticias oficiales del óbito llegaban con retraso a los dominios americanos y a veces no eran las primeras en llegar, pues la población se transmitia vía oral la nueva quizá recibida en algún puerto o por boca de un viajero, que suplia las carencias técnicas como canal de información.

La muerte del rey tenía como consecuencia paralela la jura de su legítimo sucesor, legitimidad de derecho u origen divino, en un acto de transmisión o relevo de la potestad regia que validaba la institución monárquica e inauguraba el nuevo rei-

45 Mejias Álvarez, M. a J., Fiesta..., pp. 73-74.

46 PANOFSKY, E., Estudios sobre Iconología, Madrid, 1984.

47 Sobre la lucha contra la distancia y su valor como clave interpretativa, vid. KameN. H., Imperio. La forja de España como potencia mundial, Aguilar, Madrid, 2003. 
nado. El cambio de monarca y la continuidad de la monarquía constituian la base del mecanismo de perpetuación de los lazos entre la América española y la Península. El formulismo al caso lo expresaba de forma sucinta, así todos los documentos oficiales, relaciones y cartas entrecruzadas para comunicar la noticia al referirse al difunto rey Carlos III añadían "que santa gloria haya" y al mencionar a Carlos IV “que Dios guarde» ${ }^{48}$. Las exequias por el soberano fallecido y la proclamación del sucesor repetían panegíricos y augurios respectivamente. De este modo, podemos conceptuar las honras fúnebres como el punto de partida de un proceso de renovación y reafirmación monárquica que culminaba con la jura del nuevo rey. Por toda la monarquía se reproducian los actos y ceremonias, con participación de toda la sociedad y diverso grado de festejos según las características del territorio. La lejanía en el caso chileno no supuso menoscabo festivo, al contrario, hacía necesario demostrar la fidelidad y adhesión de tan distantes súbditos e integrar y cohesionar a todos los grupos, castas y estamentos sociales en torno a la lealtad real por encima de la pigmentocracia interna y el mundo fronterizo meridional.

La continuidad dinástica, la sucesión del linaje regio y la sanción una vez más de la forma de gobierno se transmutaba en fiestas, de marcado carácter, alcance e intencionalidad política en una escenificación del poder mediante espectáculos públicos que proyectaban el mensaje legitimador a la multitud, que reconocía, aceptaba y proclamaba al rey en aquellos espacios urbanos de sociabilidad más sensibles del orbe hispanoamericano ${ }^{49}$. Una auténtica finalidad de manifestación colectiva de fidelidad real en la distancia por parte de toda la sociedad indiana, aglutinada gracias al «Señor natural» incluso en el finisterre chileno de sus dominios, por lo que el orden colonial jerarquizado quedaba integrado y ratificado por sus remotos vasallos ${ }^{50}$. La proclamación real unificaba al conjunto de la sociedad en la fidelidad y consentimiento público de vasallaje al soberano e inauguraba una nueva etapa de prosperidad tras las honras fúnebres, al tiempo que mostraba de forma evidente las diferencias internas y complejidad de la sociedad en Indias.

48 Carlos III falleció a finaies de 1788, heredando la corona su hijo proclamado como Carlos IV el 17 de enero de 1789; así, en el plazo de un mes concluyó el mecanismo sucesorio y legitimador en el centro de poder de la Monarquia, alcanzando posteriormente los más distantes territorios hispánicos. En el caso chileno las festividades de proclamación del nuevo rey tuvieron lugar a principios de noviembre de 1789, once meses tras el óbito del monarca anterior y diez tras la proclamación peninsular.

49 A este respecto: GuerRA, F.-X. y Lempériére, A. (Coord.), Los espacios públicos en Iberoamérica. Ambigüedades y problemas. Siglos xvili-xix, FCE, México, 1998.

50 L.a idea-fuerza lealtad estaba presente desde las exequias y era el núcleo de la jura posterior, vid. Sentimientos leales de ternura que la provincia de Córdoba del Tucumán, virreinato de Buenos Aires, manifestó en el fallecimiento de su católico monarca, el señor don Carlos III..., Madrid, 1790. Cit. en LóPEZ Cantos, A., Juegos, fiestas y diversiones en la América española, MAPFRE, Madrid, 1992, p. 128. 